Journal of Machine Engineering, 2021, Vol. 21, No. 2, 91-101

ISSN 1895-7595 (Print) ISSN 2391-8071 (Online)

Received: 01 November 2020 / Accepted: 13 February 2021 / Published online: 10 June 2021

additive manufacturing, $L P B F$ process, post-processing, reaming

\author{
Heiko TEICH ${ }^{*}$ \\ Clemens MAUCHER ${ }^{1}$ \\ Hans-Christian MÖHRING ${ }^{1}$
}

\title{
INFLUENCE OF LPBF PARAMETERS AND STRATEGIES ON FINE MACHINING OF PRE-BUILT BORES
}

\begin{abstract}
Additive manufacturing changes the classical possibilities of production. However, post-processing is usually unavoidable for these components to achieve functional performance. To obtain an optimum product, knowledge of the characteristics of the additive manufactured part and the machining mechanisms depending on these characteristics is required. In this paper, the influence and the interaction of the laser powder bed fusion process parameters on the subtractive post-processing are shown. The effects of the parameters on the geometry of bores are examined and subsequently the precision machinability is analysed using reaming. In addition, a process simulation is carried out to correlate the simulated deformation to the required machining allowance for subsequent reaming. The aim of this investigation is to examine the capabilities of the laser powder bed fusion process to produce bores at angles of $90^{\circ}$ (vertical), $60^{\circ}$ and $45^{\circ}$ that can be machined directly with a reaming tool without the need for drilling.
\end{abstract}

\section{INTRODUCTION}

Additive Manufacturing (AM) technologies offer highly complex, individually adaptable geometries to be manufactured, that cannot be produced by conventional methods [1]. With the laser powder bed fusion (LPBF) technology metal components can be manufactured in small quantities with high productivity and material efficiency. Materials such as maraging steel and titanium are especially suited for lightweight components used in high-end industries such as the aerospace sector. Maraging steel specifically offers a rare combination of high tensile strength and high fracture toughness, which makes it particularly suitable for structures that require strength and damage tolerance [2].

In the LPBF process, a laser is used as an energy source to selectively melt material in the powder bed to build up a component layer by layer. Due to this layered structure, support structures on overhanging surfaces with angles lower than $45^{\circ}$ are required to dissipate heat and to avoid thermally induced deformations [3]. Above $45^{\circ}$ bores can be built without

\footnotetext{
${ }^{1}$ Institute for Machine Tools, University of Stuttgart, Stuttgart, Germany

*E-mail: heiko.teich@ifw.uni-stuttgart.de

https://doi.org/10.36897/jme/133344
} 
additional structures, but post-processing is necessary due to the relatively rough surfaces and insufficient shape tolerances [4]. This post-processing is often done with subtractive machining processes, especially for functional surfaces [5].

In recent years, several authors have examined machining of additively produced parts. Iquebal et al. [6] investigated the possibility to use finishing operations for near net shape AM components to improve surface integrity with minimal machining effort. The effects of drilling parameters on the bore surface integrity of AM manufactured components have been investigated by Karabulut et al. [7]. Astakhov et al. [8] compared drilling of additively produced components to the processing of cast components and proposed to adapt special tool designs to fine machine AM manufactured cored holes.

In this article, the influence and interaction of the LPBF process parameters on the subtractive post-processing are shown based on the reaming process. Reaming is one of the fine machining processes and serves to improve the bore quality regarding geometric tolerances and surface roughness, typically achieving tolerances of H7. In conventional manufacturing, precision bores need to be drilled first (rough pass) and are subsequently reamed (finish pass) with a precision tool. Due to the high accuracy and the associated small chip space of the tool, reamers can only cut a limited amount of material [9]. The goal of this research is to examine if AM can produce sufficiently accurate geometry to fit within the restrictions imposed by the reaming process and yield the high-quality surface characteristics expected from fine machining. The properties of the resulting components and the quality characteristics within the individual manufacturing steps and in the interaction of successive machining processes must be considered. This interaction is particularly important for bores in different orientations with increased surface quality requirements, such as for bearing seat or sealing fits.

\section{EXPERIMENTAL SETUP}

\subsection{SPECIMEN DESIGN}

In order to exclude as many influences of the LPBF process on the geometry as possible, the specimens are designed as cylinders with the same outer diameter and with a varying central bore geometry. The central bore is given a varying diameter $(D 1)$ between $15.6 \mathrm{~mm}$ and $15.8 \mathrm{~mm}$.

The first samples are built vertically with a varying border count (including total fill) and exposure sequence (hatch/border or border/hatch) to investigate the as-built condition (see Table 2 in Sec. 3.1). Total fill is the option to completely fill the hatch with adjacent border scans. Furthermore, some samples are tested with a double scan approach to examine its influence, which is adapted from Černašejus et al. [10]. Double scan means all border paths are scanned twice for each layer.

The main sample set is built to investigate machining influences and resulting surface quality. To understand the influence of different bore orientations, inclinations of $90^{\circ}, 60^{\circ}$ and $45^{\circ}$ to the build plate are investigated. The dimensions of the test specimens and 
the build-up direction during the LPBF process are shown in Fig. 1, together with further sample features. In addition, specimens with full density are produced, to compare the achievable surface quality between reaming a pre-built bore and combined drilling and reaming. Three samples are built for each parameter combination.
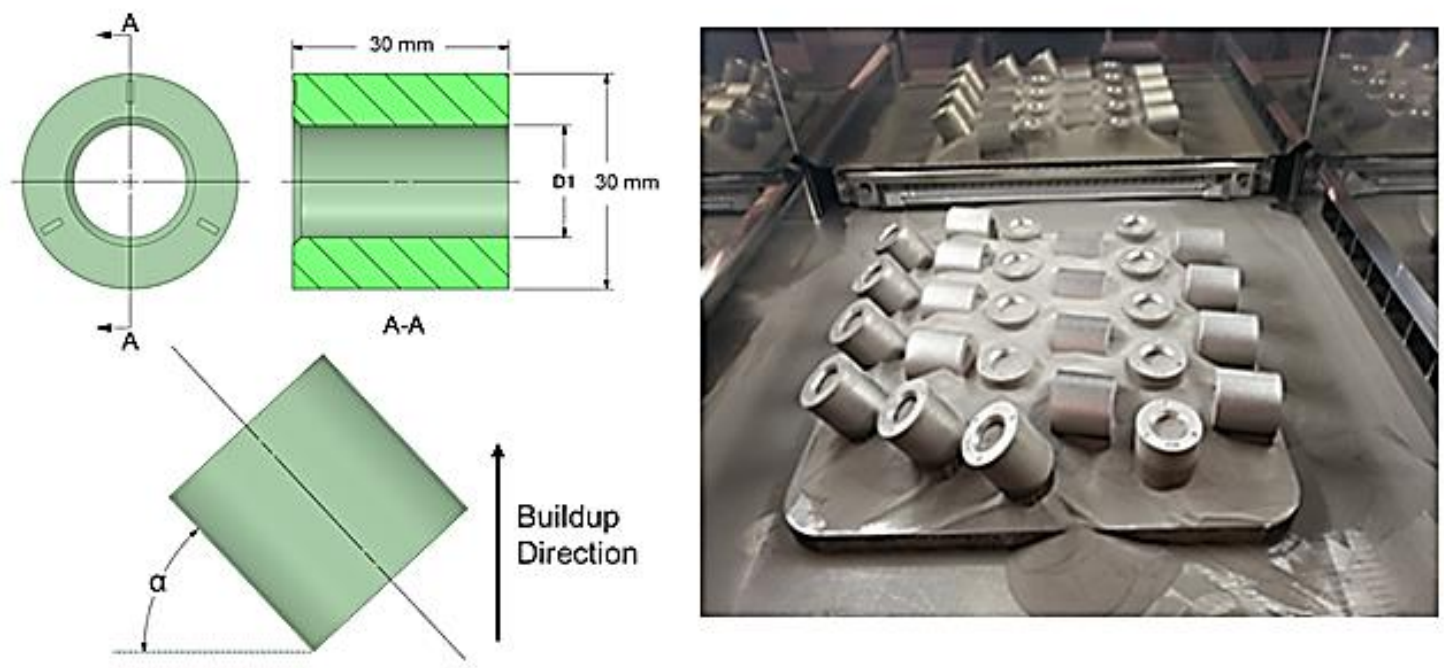

Fig. 1. Sample dimensions and design features (left), samples after printing (right)

\subsection{ADDITIVE MANUFACTURING}

A LPBF Machine RenAM 500Q from the company Renishaw is used for manufacturing of the specimens. The specimens are made from maraging steel M300, also known as tool steel 1.2709. For quality assurance, the powder is examined regarding particle size distribution. It is found that the properties are within the range of a typical LPBF powder [11] with the following values: $\mathrm{D} 10=24.45 \mu \mathrm{m}, \mathrm{D} 50=35.47 \mu \mathrm{m}$ and $\mathrm{D} 90=47.79 \mu \mathrm{m}$. The applied process parameters for manufacturing are listed in Table 1.

Table 1. LPBF process parameters used for material 1.2709

\begin{tabular}{|l|c|}
\hline Process parameter & Value \\
\hline Layer Thickness & $50 \mu \mathrm{m}$ \\
\hline Particle Size Range & $25-50 \mu \mathrm{m}$ \\
\hline Laser Power Border & $150 \mathrm{~W}$ \\
\hline Laser Scan Speed Border & $300 \mathrm{~mm} / \mathrm{s}$ \\
\hline Laser Power Hatch & $250 \mathrm{~W}$ \\
\hline Laser Scan Speed Hatch & $1000 \mathrm{~mm} / \mathrm{s}$ \\
\hline Atmosphere & Argon \\
\hline Bore Diameter $(D 1)$ & $15.6-15.8 \mathrm{~mm}$ \\
\hline
\end{tabular}




\subsection{MACHINING}

Experiments are conducted using a Hermle UWF 1202 machining center with emulsion cooling. The specimens are clamped with a three-jaw chuck. For drilling, a carbide drill with two cutting edges, internal cooling, a diameter of $15.8 \mathrm{~mm}$ and proprietary nanoFIRE coating from the company Gühring is used. A cutting speed of $v_{c}=65 \mathrm{~m} / \mathrm{min}$ and feed of $f=0.315$ $\mathrm{mm} / \mathrm{rev}$ are chosen for the drill. For reaming, a straight-fluted high-performance carbide reaming tool with an ALCrN-Coating, diameter of $16 \mathrm{~mm}$ and tolerance class of $\mathrm{H} 7 \mathrm{by}$ the Company Paul Horn GmbH is used.

The cutting parameters are set to $v_{c}=30 \mathrm{~m} / \mathrm{min}$ and $f=0.54 \mathrm{~mm} / \mathrm{rev}$. Solid samples are drilled first and then reamed. Samples with a pre-built bore are reamed in their as-built condition (called as-built reaming within this paper).

Surface roughness of the machined inner bore is measured for each specimen on five lines along the axis using a surface measuring device Mitutoyo Formtracer S3000. Circularity and Cylindricity is measured on a Mitutoyo coordinate measuring machine (CMM) retrofitted by Renishaw with a REVO-2 5-Axis system, RSP2 scanning head with a RSH250-6×10 stylus (ball diameter of $6 \mathrm{~mm}$ ). The optical investigation is performed with a digital microscope VHX-6000 from Keyence.

\subsection{SIMULATION}

A process simulation of the LPBF process is carried out with ANSYS Additive Print to correlate the simulated deformation to the required machining allowance for subsequent reaming. In ANSYS Additive Print, the "thermal strain" calculation method is selected, which takes the laser path and anisotropy directly into account using the production data of the LPBF system. This simulation method provides the highest degree of accuracy by predicting how thermal cycling influences strain accumulation at all locations within the part. ANSYS employs a "thermal ratcheting" algorithm for this purpose. After calculating strain magnitude at each location, the result is passed to the mechanics solver as anisotropic strain based on magnitude and local scan vector direction.

\section{RESULTS}

\subsection{INFLUENCE OF AM PROCESS STRATEGIES ON SURFACE QUALITY}

The effects of build parameters "border count", "hatch / border sequence" and "double scan border exposure" are first examined to investigate the influence on subsequent reaming of the samples in as-built condition. Table 2 lists the parameters and the samples used for the border influence experiments, which are all built in vertical orientation with an inner bore diameter of $15.8 \mathrm{~mm}$. 
Table 2. Overview of the varied parameters used to inspect as-built surface quality

\begin{tabular}{|c|c|c|c|c|c|}
\hline \multirow{2}{*}{ Drawing } & \multirow{2}{*}{$\begin{array}{l}\text { Border } \\
\text { Count }\end{array}$} & \multirow{2}{*}{ Sequence } & \multirow{2}{*}{$\begin{array}{c}\text { Double } \\
\text { Scan }\end{array}$} & \multicolumn{2}{|c|}{ Samples } \\
\hline & & & & Count & ID \\
\hline \multirow[b]{3}{*}{ IIIIIIIA } & \multirow{3}{*}{1} & Border - Hatch & \multirow{2}{*}{ No } & 3 & 1 \\
\hline & & Hatch - Border & & 3 & 2 \\
\hline & & $\mathrm{B}-\mathrm{H}-\mathrm{B}$ & Yes & 3 & 3 \\
\hline \multirow{3}{*}{ WIII) } & \multirow{3}{*}{2} & Border - Hatch & \multirow{2}{*}{ No } & 3 & 4 \\
\hline & & Hatch - Border & & 3 & 5 \\
\hline & & $\mathrm{B}-\mathrm{H}-\mathrm{B}$ & Yes & 3 & 6 \\
\hline & \multirow{3}{*}{$\begin{array}{l}\text { Total } \\
\text { Fill }\end{array}$} & Border - Hatch & \multirow{2}{*}{ No } & 3 & 7 \\
\hline & & Hatch - Border & & 3 & 8 \\
\hline & & $B-H-B$ & Yes & 3 & 9 \\
\hline
\end{tabular}

Figure 2 shows the roughness comparison between the samples after removing them from the build plate. Each parameter variation is applied 3 times and each sample is measured five times. All blue coloured results are samples which are built with one border, orange samples with two borders and green samples with the total fill option. Within those groups the "hatch and border sequence" is changed for the first and the second sample set respectively and the third has the border scanned twice. It is evident from the results, that a count of two borders is superior to just one border. Furthermore, the results show an indication that the sequence in which the border and hatch are scanned also matters.

The double scan border exposure samples (ID 3, 6 and 9) do not show any improvement in surface roughness, but rather amplified negative effects, as can be seen with samples ID 9. In addition, the double scan strategy does not influence the cylindrical shape and takes more time when the laser tracks are scanned twice. The total fill samples show defects on the top surface when inspecting them visually and have a wider spread in measured roughness. The "double scan" and "total fill" strategies are therefore discarded.

The cylindricity in the as-built condition of vertical samples does not seem to be affected by border strategy settings. Both one and two borders result in a cylindricity in as-built condition between 140-240 $\mu \mathrm{m}$ for vertical samples (see Fig. 2).

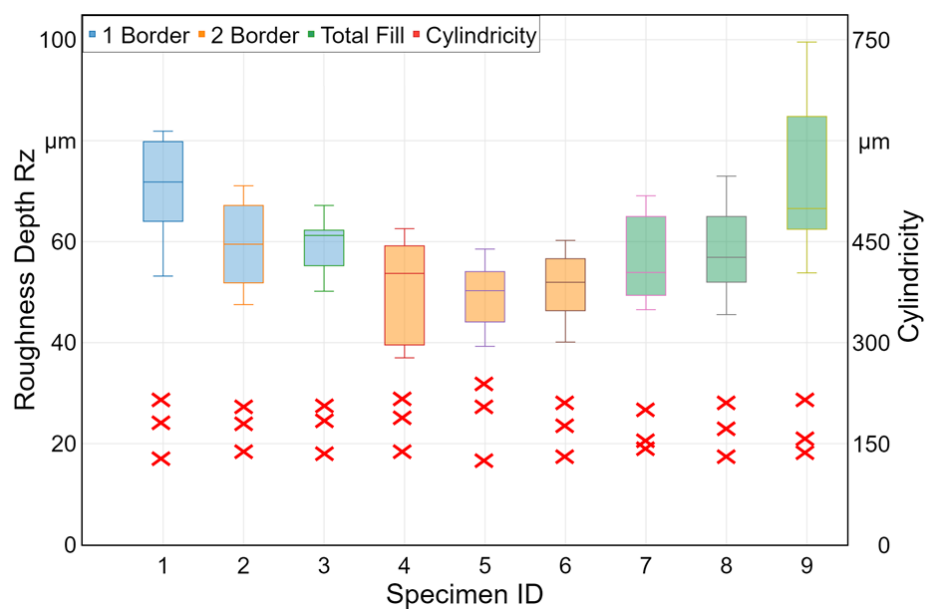

Fig 2. Roughness comparison for different build parameters (three samples each) 
In conclusion of the border strategy influence on surface quality, it can be said:

- Border parameters have no discernible influence on cylindricity and straightness of the as-built condition.

- Double scan has no significant influence on as-built surface roughness.

- Parameter sets with two borders provide the best surface roughness in as-built condition.

\subsection{INFLUENCE OF BORE ORIENTATION}

AM manufactured parts cannot always be freely oriented, and bores can be in different orientations on the build plate. It is therefore important to know the influence of various orientations on bores when building parts with the LPBF process. Here, samples are built with an angle of $90^{\circ}$ (vertical), $60^{\circ}$ and $45^{\circ}$ to the build plate to examine the effects of bore orientation.

Figure 3 shows the roughness for bores in different orientation measured in the as-built condition, meaning no post-processing has been performed yet. The vertical axis shows the roughness depth $\mathrm{Rz}$ in $\mu \mathrm{m}$. The horizontal axis splits the measurements into three groups: measurements on bores in $90^{\circ}$ (vertical), $60^{\circ}$ and $45^{\circ}$ orientation. Each orientation uses measurements from six samples and all outliers are removed. The outliers are measured on the overhanging surfaces, also called down-skin, of the $45^{\circ}$ and $60^{\circ}$ samples. Their Rz values are in the range of 150 to $250 \mu \mathrm{m}$ for the $45^{\circ}$ samples and 100 to $120 \mu \mathrm{m}$ for the $60^{\circ}$ samples. The boxplot shows that the orientation of bores has an influence on the resulting surface quality, even with down-skin measurements removed. While the median and lowest achieved $\mathrm{Rz}$ values are comparable between the sample orientations, the maximum differs significantly, from $64 \mu \mathrm{m}$ for vertical up to $90 \mu \mathrm{m}$ for $45^{\circ}$ samples. This can be attributed to the staircase-effect [12].

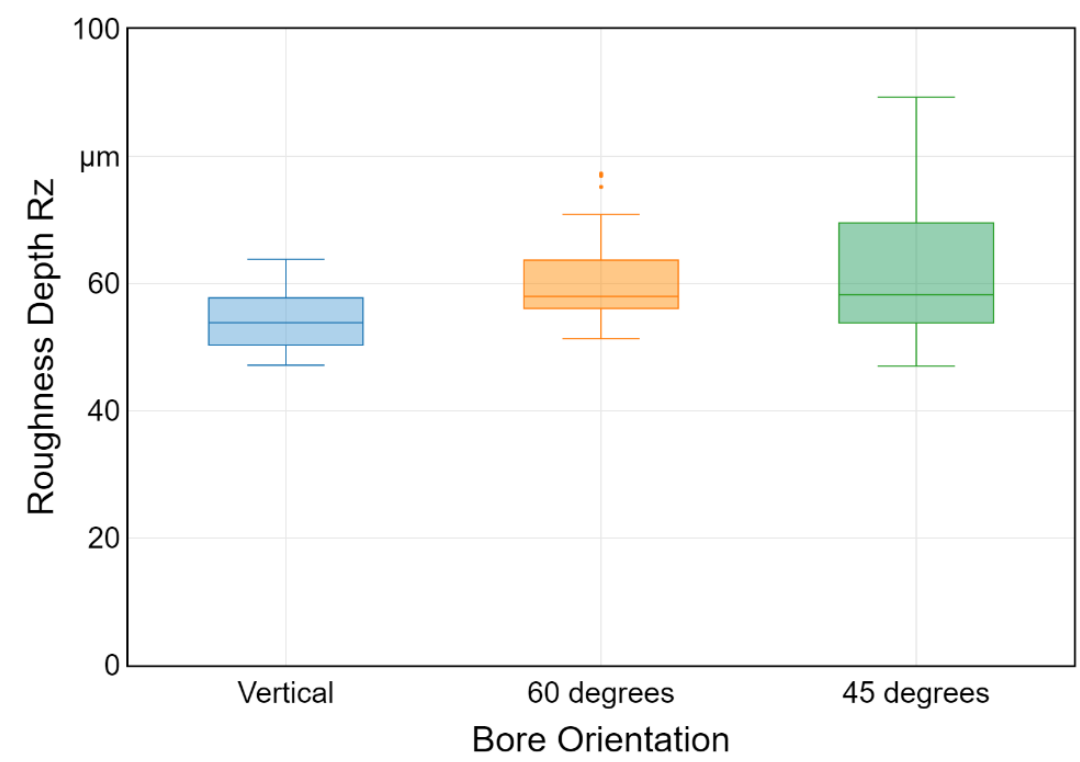

Fig 3. Roughness depth Rz in the "as-built" condition and different bore orientations 
Figure 4 visualizes the deviation in shape for $45^{\circ}$ and $60^{\circ}$ samples in their as-built condition. The simulated results (Fig. 4 above) and measurements (Fig. 4 below) show good agreement especially in the marked regions (marker A and B). The simulation predicts that there will be a higher displacement in the bottom region which can be measured inside the bore. A deviation up to $120 \mu \mathrm{m}$ from the nominal cylinder form can be seen. The simulation tool does not consider downskin effects, resulting from the meltpool penetrating several layers instead of just one on each scan pass. This leads to the shape deviation that can be seen at marker $\mathrm{C}$ of the measurement plot, but not on the downskin surface of the simulation. The same agreement between simulation and measured results for $60^{\circ}$ samples can also be observed. The magnitude is around $70 \mu \mathrm{m}$ in this bore orientation and located closer to the bottom of the sample (marker B). Downskin effects are also much less prevalent for this orientation (marker D). The measurement of the vertical bores and the corresponding simulation also show the same agreement, with a lower shape deviation and a symmetrical appearance.

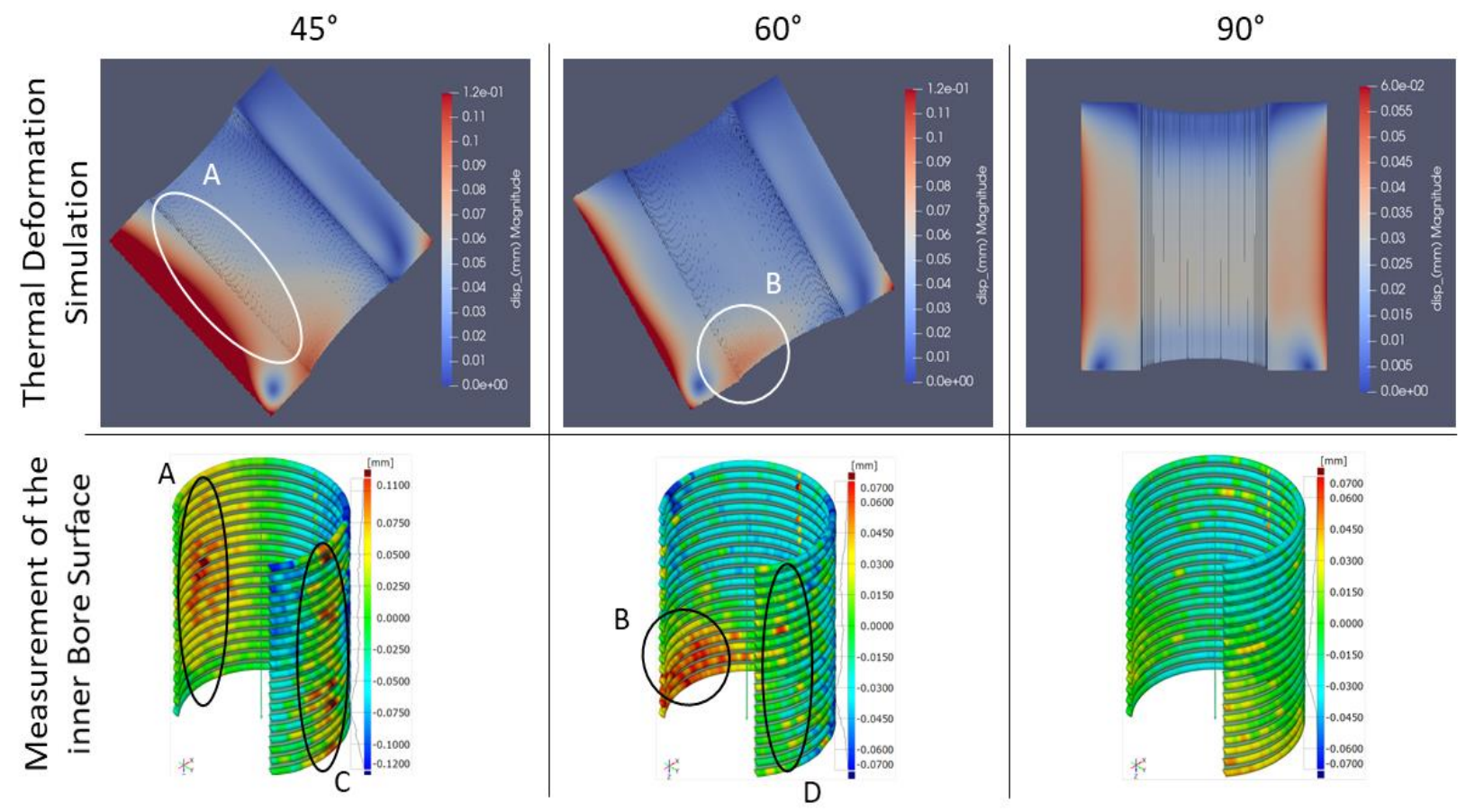

Fig. 4. Deformation comparison between the LPBF process simulation and the form measurement

The results show that building bores vertically results in a better surface roughness in the as-built condition. The main findings from the bore orientation analysis can be summed up as follows:

- Bores in vertical orientation achieve the best cylindricity, straightness and roughness in as-built condition.

- Angled bores have lower surface quality in as-built condition not only because of downskin effects, but also because of higher warpage compared to vertical bores.

- Simulations show predictions for warpage that closely match the measurements. 


\subsection{MACHINING AND RESULTING SURFACE PROPERTIES}

After measuring the "as-built" condition and centering the samples in the machine, reaming of the pre-built bore is carried out. Based on the process simulation, a machining window for reaming can be defined based on the deformation rate. This is achieved by defining the maximum deformation as the minimum allowance, taking into account the process-related basic deviation of the surface quality [13].

Samples build in vertical direction $\left(90^{\circ}\right)$ have the best cylindricity and reaming those samples with a prebuild diameter of $D 1=15.8 \mathrm{~mm}$ results in a high-quality surface in most areas. Therefore, the roughness and CMM measurements produce acceptable characteristic values. The visual inspection however, shows that there are still areas with remaining surface porosity of the as-built surface present. This can be seen in Fig. 5 (center) with the corresponding measurements. The as-built condition can be seen on the left in Fig. 5 . Reaming with a prebuild bore diameter of $D 1=15.7 \mathrm{~mm}$ (machining allowance of $0.3 \mathrm{~mm}$ ) provides good results and can be seen on the right in Fig. 5.

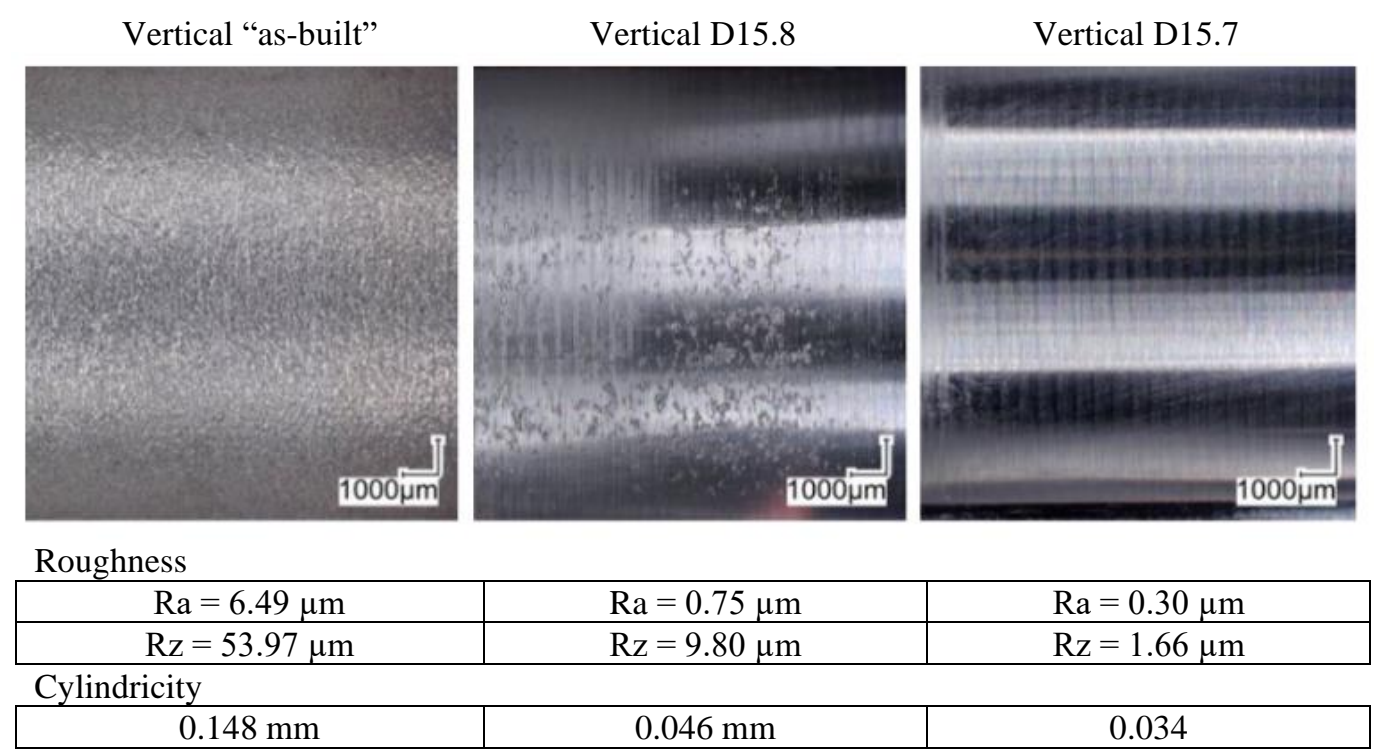

Fig. 5. Surface quality of samples built in vertical direction $\left(90^{\circ}\right)$ after reaming

Due to increasing deformation effects with decreasing inclination, a machining allowance of $0.3 \mathrm{~mm}$ is not sufficient for $60^{\circ}$ samples. Increasing the machining allowance to $0.35 \mathrm{~mm}$, with a prebuild diameter of $D 1=15.65 \mathrm{~mm}$, results in a good surface quality after as-built reaming.

The same effect is present with the $45^{\circ}$ samples, which exhibit an even higher deformation in addition to surface deterioration at down-skin surfaces, due to meltpool layer penetration. Therefore, reaming needs more allowance to provide a constant cut through the material. An allowance of $0.4 \mathrm{~mm}(D 1=15.60 \mathrm{~mm})$ proved sufficient to achieve a good surface finish after reaming. It is still possible to machine the samples with this higher machining allowance, although the recommended value is in the range between 0.2 to $0.3 \mathrm{~mm}$ 
for the utilized tool with a diameter of $16 \mathrm{~mm}$. It should be noted, however, that this recommendation is based on the conventional drilling - reaming process chain, and not the as-built reaming process as investigated in this paper.

The as-built condition shows a cylindricity range between $140-370 \mu \mathrm{m}$, and a straightness range between $22-48 \mu \mathrm{m}$. The reaming operation improves those values for all samples and narrows the range. After as-built reaming the cylindricity is between $15-47 \mu \mathrm{m}$ with the median at $30 \mu \mathrm{m}$, and the straightness is between 2-7 $\mu \mathrm{m}$ with the median at $4 \mu \mathrm{m}$ (see Fig. 6).

Figure 7 shows the roughness depth $\mathrm{Rz}$ comparison for samples after reaming. In addition, for comparison reasons samples without a prebuild bore are manufactured, drilled and then reamed. The roughness after as-built reaming is measured to be between 1.3-2.8 $\mu \mathrm{m}$, compared to $1.3-2.5 \mu \mathrm{m}$ for the solid reference samples after drilling and reaming.

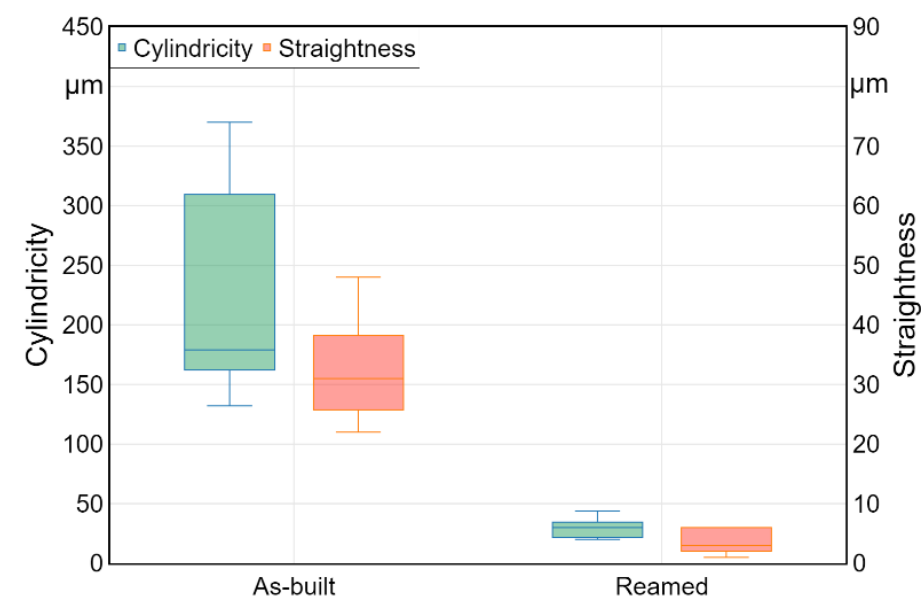

Fig. 6. Cylindricity and straightness measurements in as-built and reamed condition for all build angles
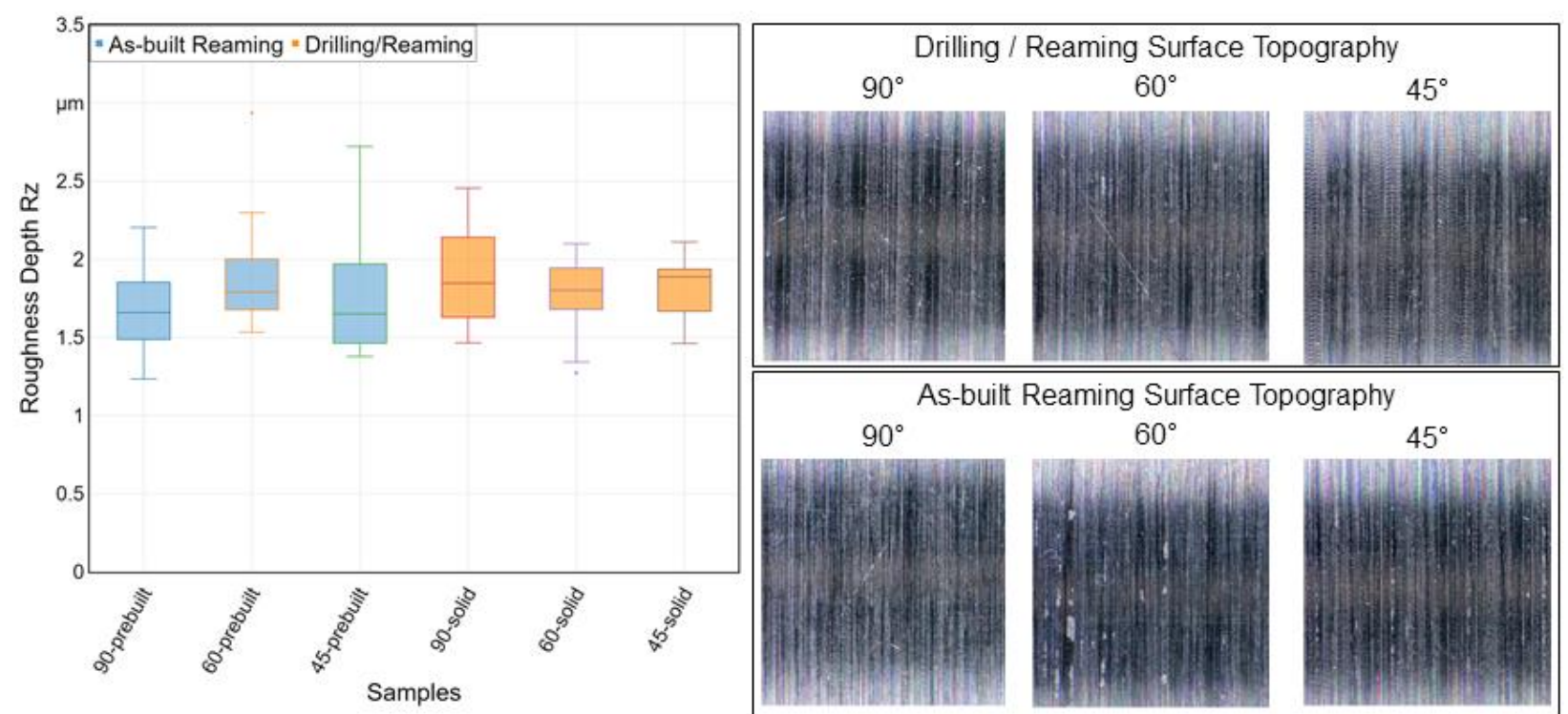

Fig 7. Roughness comparison after as-built reaming with the carbide reamer and drilling and reaming (left) and resulting surface (right) 
CMM measurements give diameter results between $16.007 \mathrm{~mm}$ and $16.018 \mathrm{~mm}$ for all samples, with no discernible trend for specific parameters within the dataset. Therefore, all samples are within the desired $16 \mathrm{H} 7$ tolerance after machining.

\section{CONCLUSION}

The interactions in the subtractive processing of additively produced samples are examined. It is achieved to design bores in additive manufacturing in such a way that as-built reaming of the pre-built bore is made possible. The drilling process step can thus be omitted. In addition, an LPBF process simulation can be used to assess whether as-built reaming is possible and which machining allowance should be provided. The most important conclusions of this paper are:

- Reaming without previous drilling is possible and can produce good results regarding surface finish and dimensional accuracy if proper care is taken in choosing the right tool and machining allowance.

- A diameter of $15.8 \mathrm{~mm}$ results in surface defects after reaming of vertical and $60^{\circ}$ samples. $0.2 \mathrm{~mm}$ is therefore not enough machining allowance for as-built reaming.

- A diameter of $15.7 \mathrm{~mm}$ with vertical samples produces very good results after as-built reaming. Roughness, cylindricity and straightness are similar to samples that are drilled before reaming.

- Bore orientation matters and requires a slightly higher machining allowance as can be seen with $60^{\circ}$ and $45^{\circ}$ samples.

Additional analysis must be conducted in order to create an analytical model for as-built reaming of additively pre-built bores with different bore sizes and orientations, based on further measurements, simulations and statistical surface models.

\section{ACKNOWLEDGEMENTS}

This article was assisted with the kind contributions of Renishaw Deutschland GmbH and Paul Horn GmbH. This work is part of the research project Ad-Proc-Add supported by the German Federal Ministry for Economic Affairs and Energy by means of the research program Cornet/IGF.

\section{REFERENCES}

[1] MÖHRING H.-C., STEHLE T., MAUCHER C., BECKER D., 2019, Prediction of the Shape Accuracy of Parts Fabricated by Means of FLM Process Using FEM Simulations, Journal of Machine Engineering, 19/1, 114-127.

[2] MOURITZ A.P., 2012, Steels for Aircraft Structures, Introduction to Aerospace Materials, Oxford, Woodhead Publishing Ltd.

[3] KRANZ J., 2014, Design Guidelines for Laser Additive Manufacturing of Lightweight Structures in TiAl6V4, Journal of Laser Applications, 27/S1, S14001.

[4] LEACH R., BOURELl D., CARMIGNATO S., DONMEZ M., SENIN N., DEWULF W., 2019, Geometrical Metrology for Metal Additive Manufacturing, CIRP Annals - Manufacturing Technology, 68/2, 677-700. 
[5] DU W., BAI Q., ZHANG B., 2016, A Novel Method for Additive/Subtractive Hybrid Manufacturing of Metallic Parts, Procedia Manufacturing, 5, 1018-1030.

[6] IQUEBAL A.S., EL AMRI S., SHRESTHA S., WANG Z., MANOGHARAN G.P., BUKKAPATNAM S., 2017, Longitudinal Milling and Fine Abrasive Finishing Operations to Improve Surface Integrity of Metal AM Components, Procedia Manufacturing, 10, 990-996.

[7] KARABULUT Y., KAYNAK Y., 2020. Drilling Process and Resulting Surface Properties of Inconel 718 Alloy Fabricated by Selective Laser Melting Additive Manufacturing, Procedia CIRP, 87, 355-359.

[8] ASTAKHOV V., PATEL S., 2019, Development of the Basic Drill Design for Cored Holes in Additive and Subtractive Manufacturing, Additive and Subtractive Manufacturing, 3, 113-148, DOI: 10.1515/9783110549775003.

[9] LAPERRIÈRE L., REINHART, G., (Eds.), 2014, CIRP Encyclopedia of Production Engineering, Springer-Verlag Berlin Heidelberg, Part F.

[10] ČERNAŠĖJUS O., ŠKAMAT J., MARKOVIC ${ }^{\sim}$ V., VISNIAKOV N., INDRISIUNAS S., 2019, Surface Laser Processing of Additive Manufactured 1.2709 Steel Parts: Preliminary Study, Advances in Materials Science and Engineering, 2019, 1-9.

[11] SPIERINGS A.B., HERRES N., LEVY G., 2011, Influence of the Particle Size Distribution on Surface Quality and Mechanical Properties in AM Steel Parts, Rapid Prototyping Journal, 17/3, 195-202.

[12] CABANETTES F., JOUBERT A., CHARDON G., DUMAS V., RECH J., GROSJEAN C., DIMKOVSKI Z., 2018, Topography of as built surfaces generated in metal additive manufacturing: A multi scale analysis from form to roughness, Precision Engineering, 52, 249-265.

[13] LALEHPOUR A., BARARI A., 2018, A More Accurate Analytical Formulation of Surface Roughness in LayerBased Additive Manufacturing to Enhance the Product's Precision, Int. J. Adv. Manuf., Technol., 96/9-12, 37933804. 